own involvement in decision-making processes.

A list of recommendations leaves practitioners and administrators, as well as politicians, ample food for thought, which, it is hoped, will contribute to easing difficult situations where decisions have to be lived through.

MARIANNE ARNDT

Research Fellow, Humboldt University, Berlin, Germany and Lecturer, University of Stirling,

Scotland

\section{Antenatal Screening and Abortion for Fetal Abnormality: Medical and Ethical Issues}

\author{
Edited by David Painton, London, \\ Birth Control Trust, 1997, 96 pages, \\ $£ 20$.
}

This review is written on the 30th anniversary of the Abortion Act 1967, a time of heightened debate on the subject, and within days of the publication of the Royal College of Obstetricians and Gynaecologists' report on fetal awareness.

Although abortion for fetal abnormality accounts for only $1-2 \%$ of the total, this book reports the proceedings of a symposium held in September 1996, under the auspices of the Birth Control Trust, to consider the ethics of, and good practice relating to, screening for fetal abnormality and subsequent management of the pregnancy should an abnormality be suspected or diagnosed. The Trust is strongly in favour of the woman having the options of antenatal diagnosis and of abortion if the fetus proves to be abnormal. Readers will not find much to challenge these views within this book.

In the opening chapter, Professor Raanan Gillon argues that the fetus is not a person and therefore not entitled to the moral respect we accord one another. As a result he is able to adopt a self-confessed liberal attitude to abortion. He considers that the developmental dividing lines enshrined in law - viability and birth - are not good criteria for deciding intrinsic moral rights; neither is the concept of sentience, which produces only an obligation not to inflict unnecessary pain. At one stage he admits to a con- tinuum of development towards full personhood. One wonders if there are not duties owed to the fetus concomitant to its position on this spectrum. If there are, what other duties may conflict with them and how much weight should be given to each at a particular time?

Some who accept abortion solely because the pregnancy is unwanted have reservations when it is requested on the grounds of fetal abnormality, perhaps because of a fear of condoning eugenics or of giving an impression that those who are disabled are somehow being devalued. Although Professor Gillon dismisses any logical connection, some debate on the reasons for aborting such pregnancies might have been apposite.

Professor Richard Lilford introduces an intellectual model with which we might assess screening nationally. As an example, he invites us to consider 100,000 pregnancies being screened for Down's syndrome. After 80,000 triple tests (often used as an initial screening for Down's syndrome to decide whether to have amniocentesis) and 3,000 amniocenteses (2,960 of which will be negative) the number of babies born with Down's syndrome will be reduced from 100 to 60 and 30 normal fetuses will have been aborted as a complication of the procedure. $\mathrm{He}$ concludes that the programme provides the community with a considerable net gain. Your reviewer finds the consideration more challenging than he might care to admit.

Dr Sue Atkinson describes the concepts of need, demand and supply; the influences affecting decision-making and the use of resources; the disparity of services offered within and between districts; the lack of continuity when a separate medical team has the contract for terminations; the introduction of tests before proper appraisal (nothing new in obstetrics and gynaecology), and the inadequacy of counselling. Little wonder the Chief Medical Officer has set up a committee on screening to select the most costeffective programmes.

Three chapters relate to problems at the level of the individual. Dr Jenny Hewison, a psychologist, presents the doctor-patient contradiction in screening - the doctor determined to find if anything is wrong and the mother hoping to prove that all is well. There are problems of compliance, of adequate information-giving and of explaining results based on probability. Many obstetricians have dealt with those who have declined a triple test but who didn't seem realise that it was impossible to perform a scan, which was either requested or clinically indicated, without observing abnormality. Ful informing a woman, maintaining he trust, without increasing her anxie? or bringing unhappiness at a time joy is a path which is individual and must be trodden subtly.

Cathy Warwick describes excelle $\vec{P}$ initiatives undertaken at King's CoE lege Hospital to ensure that midwive are adequately prepared, throug workshops and an information pack age, to provide information, suppone and counselling before and after inveso tigations are carried out.

Joanie Dimavicius is the director an organisation whose name, Suppoge Around Termination for Abnormality conveys the gist of her chapter. Infoy mation must be clear, accurate an consistent, while the support must extend to both parents and staff.

We are then reminded that it falls the doctor to interpret such words io the Abortion Act as "substantial" an "seriously (handicapped)" when refe ring to the risk and the effect of the fetal abnormality. Should this be sक्षे There is agreement that while wide discretion is permitted, a list of cond tions would prove unworkable.

Two gynaecologists report the prae tice of feticide, at gestations beyon 15-18 weeks, since "it is appropriate that there is no sign of life abortion". There is no discussion कूn whether this is to prevent fetal suffe ing or a potential charge against tige doctor involved should the live-bon baby die.

Mr Ian MacKenzie demonstrates the efficiency of newer abortifacien in reducing abortion time and side effects. The working diagnosis couff be confirmed in $99 \%$ of cases. Then Mr Eric Jauniaux describes minimis ing the pain and duration of tho procedure by emptying the uteress using instruments, under general $a B-$ aesthesia, even up to 22 weeks. T fetus is likely to be delivered "in frast ments" (Mr David Paintin's wordo not mine) prohibiting viewing by parents or examination by a pathologist, yet this method was chosen $90 \%$ of patients offered it or a medial procedure in this study and accour for over $75 \%$ of elective secorod trimester abortions in the USA.

Finally, Dr Pamela Johnston com: pares the roles of the generalist an specialist obstetrician, the former $\overrightarrow{\mathrm{CO}-}$ ordinating the seamless delivery of 
local and central services and someone to whom the patient may ever turn.

With contributions by the editor, who is also director of the Birth Control Trust, and interesting discussions complementing each section, we are given insight into the strengths and weaknesses of those involved in this aspect of antenatal care. Each profession has its own skill but it is as a team that maximum success is achieved. This is a short yet challenging book, suitable for all members of each team to read before putting the best aspects of quality care into practice.

ROBERT MCC MCMILLEN

Director of Woman and Child Health, Antrim Hospital

\section{Informative}

\section{Paternalism: Studies in the Ethics of Promoting and Predicting Health}

\author{
Nina Nikku, Linkoping, Sweden, \\ Linkoping Studies in Arts and \\ Science No 55, 1997, 356 pages, \\ $\mathrm{kl} 10.00$.
}

This book is a well-researched dissertation in medical ethics. The focus of its discussion, which is in "the mainstream" of "the Anglo-Saxon analytic tradition", (page 66) is on the potential for ethical conflict "between the beneficence of health promotion and the individual's right to selfdetermination" (page 337). For its wide survey of views, its own original (though not unproblematic) contentions, and its relevance to present debates, this dissertation will be of interest both to students and teachers of medical ethics.

According to the author, when an action performed with the intention of benefiting the recipient - but without his/her informed consent - is granted priority over the ability of the individual to decide and act on his/her own, that is, is granted priority over his/her putative "right to selfdetermination," we have a paternalistic action. This description contrasts with more familiar views that restrict the notion of paternalistic action to actions where the recipient is coerced for his own good; for it is precisely the author's contention that "people can have their self-determination infringed also in situations where they are neither coerced, deceived nor forced into a certain action" (page 338). This thesis is illustrated with reference to various kinds of health information, the latter being linked to an analysis of paternalistic action of the type that the author calls "informative paternalism".

Thus the book has two main parts. Part 1 presents a survey and clarification of the notions of paternalistic action and "informed consent" (that is, the broad range of notions referring to the individual's sanction in one way or another), and of various forms of justification of paternalistic actions, as including justifications resting on different modes of consent (that is, by appeal to individual, future, hypothetical, collective, and proxy consent), as well as various kinds of liberalist and consequentialist positions. It is from this survey that the author's own proposal emerges, namely, that an action performed with the informed consent of the recipient is not to be classed as paternalistic. And here it is also maintained that a paternalistic action with respect to a prior consent which is subsequently withdrawn is not possible, where this is taken to include those cases in which the individual, like Ulysses in the face of the Sirens, has foreseen a weakness of his will and given a "self-binding prior consent" (pages 74-81).

In part 2 the different types of moral justification which have been outlined are employed by the author as an instrument of analysis for the conflicts to which she calls attention here, namely those between what she identifies as the "two fundamental values" of the right to selfdetermination and information paternalism. Thus the "justificatory frameworks" are variously applied to case studies in the area of health promotion. Here the examples selected all pertain to health information which is in some way "opportunistic", that is, unrequested by the recipient, and which is intended "to steer" his behaviour in the direction which the informer deems to be most beneficial for him, but in a manner that may appear to be insensitive, unwelcome, alarming, or intrusive upon personal privacy. The cases concern, firstly, general health information of the kind that one may be used to hearing from one's general practitioner, concerning weight, smoking, exercise, diet, alcohol consumption, and so forth; and, secondly, special "predictive" information, for instance, from state-ofthe-art private clinics (perhaps contemplating future business), concerning genetic disposition for disease in an individual, such as Huntington's Chorea. In all this, the author's intention is to yield an appreciation of what it may be important (she does not say "necessary") to consider when morally judging a paternalistic action (as per her description) and when making a decision as to whether to perform the action.

The author, then, has tied the notion of paternalistic action to the absence of informed consent. The stated reason for this move is a methodological one. She seeks a "morally neutral" definition of paternalistic action, one which presupposes no particular set of ethical judgments and would thus allow her to leave the moral evaluation of the action "until after the definition" (page 144) - in contrast to those definitions (of Gerald Dworkin, J S Mill, Charles N Culver, Bernard Gert, and others) which she has reviewed and all of which were seen to import an ethical judgment of paternalistic action into its definition (page 35).

However, one wonders whether the definition that the author herself proposes - one which excises informed consent from the notion of a paternalistic action - is not itself already informed by a negative moral evaluation of the notion. This suspicion is confirmed subsequently, in the author's case studies. Here the preeminence which she attaches to the right of the individual to decide and act for himself, if not to a liberal individualism, becomes evident, for she always plumps for a maximization of self-determination, as against paternalistic action. The latter, for her, seems to have an inherent negative connotation, although to preserve her putative "meta-ethical" neutrality she allows that there are ways in which the action may be found to be a morally justified one.

There is another aspect of the author's central argument which seems problematic. She contends that bona fide health information, given to us without our "permission" but meant to steer us towards a course of action considered best for us, is liable to conflict with, or infringe, our right to, or capacity for, self-determination (she does not clearly distinguish "right" from "capacity" in this connection). However, it is difficult to see 